\title{
Salivary biomarkers in patients with psoriasis - a meta-analysis
}

\author{
Biomarkery w ślinie pacjentów z łuszczycą - metaanaliza
}

Houshang Nemati', Masoud Sadeghi',3

'Fertility and Infertility Research Centre, Health Technology Institute, Kermanshah University of Medical Sciences, Kermanshah, Iran 2 Medical Biology Research Centre, Kermanshah University of Medical Sciences, Kermanshah, Iran

${ }^{3}$ Students Research Committee, Kermanshah University of Medical Sciences, Kermanshah, Iran

'Centrum Badań nad Niepłodnością i Bezpłodnością, Instytut Technologii Zdrowia, Uniwersytet Medyczny Kermanshah, Kermanshah, Iran ${ }^{2}$ Centrum Badań Biologii Medycznej, Uniwersytet Medyczny Kermanshah, Kermanshah, Iran

${ }^{3}$ Naukowe Koło Studenckie, Uniwersytet Medyczny Kermanshah, Kermanshah, Iran

Dermatol Rev/Przegl Dermatol 2021, 108, 105-116

DOI: https://doi.org/l 0.5 | |4/dr.202।. 107280

ADDRESS FOR CORRESPONDENCE/
AUTOR DO KORESPONDENCJI:
Masoud Sadeghi MSc
Medical Biology Research Centre
Students Research Committee
Kermanshah University
of Medical Sciences
Kermanshah, Iran
phone: +989185960644
e-mail: sadeghi_mbrc@yahoo.com

\begin{abstract}
Introduction. Psoriasis is a chronic, inflammatory cutaneous disease with an unclear aetiology. Several biomarkers have been investigated for their significance in clinical practice.

Objective. This meta-analysis aimed to evaluate the salivary biomarkers in psoriatic patients compared to controls.

Material and methods. The PubMed, Scopus, Web of Science, and Cochrane Library databases were searched from the beginning of each database. The mean differences (MDs) or odds ratios (ORs) with 95\% confidence intervals (CIs) in all studies were analysed using Review Manager 5.3 software.

Results. Fourteen studies were analysed in the meta-analysis. Investigating salivary a-amylase, cortisol, IgA, interleukin- $1 \beta$, candida incidence, antipyrine clearance, sodium, potassium, chloride, and flow rate levels, there was a significant difference between psoriatic patients and controls in a-amylase $(\mathrm{MD}=12.69 \mathrm{IU} / \mathrm{ml})$, interleukin- $1 \beta(\mathrm{MD}=1.60 \mathrm{pg} / \mathrm{ml})$, and candida incidence $(\mathrm{OR}=7.64)$, respectively. Some salivary biomarkers such as a-amylase, interleukin-1 $\beta$, and candida incidence were significantly higher in the patients with psoriasis than in the controls.
\end{abstract}

Conclusions. The results indicate that saliva analysis is a valid noninvasive tool which may be used to monitor inflammation in psoriasis.

\section{STRESZCZENIE}

Wprowadzenie. Łuszczyca jest przewlekłą chorobą zapalną skóry. Wiele biomarkerów łuszczycy analizowano pod względem ich potencjalnej przydatności w praktyce klinicznej.

Cel pracy. Ocena biomarkerów obecnych w ślinie u pacjentów z łuszczycą w porównaniu z grupą kontrolną.

Materiał i metody. Przeszukano bazy danych PubMed, Scopus, Web of Science i Cochrane Library. Średnie różnice (mean difference - MD) lub ilorazy szans (odds ratio - OR) wraz z 95\% przedziałami ufności (confi- 
dence interval - CI) we wszystkich analizach obliczono za pomocą oprogramowania Review Manager 5.3.

Wyniki. W metaanalizie uwzględniono 14 badań. Analizując obecność w ślinie $\alpha$-amylazy, kortyzolu, immunoglobuliny A i interleukiny $1 \beta$, a także częstość występowania drożdży z rodzaju Candida, klirens antypiryny, stężenia sodu, potasu, chlorków i natężenie przepływu śliny, znamienną różnicę pomiędzy pacjentami z łuszczycą a grupą kontrolną stwierdzono wyłącznie pod względem stężenia a-amylazy (MD = 12,69 $\mathrm{IU} / \mathrm{ml})$, interleukiny $1 \beta(\mathrm{MD}=1,60 \mathrm{pg} / \mathrm{ml})$ i częstości występowania Candida (OR $=7,64)$. Stężenia niektórych biomarkerów obecnych w ślinie, m.in. a-amylazy i interleukiny $1 \beta$, a także częstość występowania drożdży z rodzaju Candida były znamiennie podwyższone u pacjentów z łuszczycą w porównaniu z grupą kontrolną.

Wnioski. Otrzymane wyniki wskazują, że analiza śliny może być wartościowym, nieinwazyjnym badaniem umożliwiającym monitorowanie stanu zapalnego w łuszczycy.

Key words: psoriasis, saliva, biomarkers, meta-analysis.

Słowa kluczowe: łuszczyca, ślina, biomarkery, metaanaliza.

\section{INTRODUCTION}

Psoriasis is a chronic, inflammatory, T-cellmediated cutaneous disease with an unclear aetiology $[1,2]$. Psoriasis is observed in almost $2 \%$ of the general population [3]. The disease is connected with a range of comorbidities [4]. Stress and mood disorders may affect the severity of psoriasis [5]. Psoriasis vulgaris is the most common form of psoriasis, and other forms of psoriasis include guttate, erythrodermic, and pustular psoriasis, the severity of which is measured by the Psoriasis Area Severity Index (PASI) [6]. Environmental and genetic factors may play various roles in the exacerbation and persistence of psoriasis [7]. Some immune factors can have a proinflammatory role and may play a role in the propagation of the inflammatory response in psoriasis $[8,9]$.

Saliva, a biological fluid containing important biological markers, is easily collected and stored [10]. Although salivary biomarkers have been known in several systemic diseases, there is still little documented on the salivary biomarkers related to psoriasis [11]. A new review has shown that salivary biomarkers may be helpful in identifying the severity and progression of psoriasis and may be valuable in the future [12].

\section{OBJECTIVE}

We aimed to investigate the salivary biomarkers in psoriatic patients as prognostic factors

\section{WPROWADZENIE}

Łuszczyca jest przewlekłą chorobą zapalną skóry, w której pośredniczą limfocyty T. Jej etiologia nie jest w pełni poznana $[1,2]$. Częstość występowania schorzenia w populacji ogólnej określa się na prawie $2 \%$ [3]. Łuszczyca jest związana z szeregiem chorób współistniejących [4]. Do czynników potencjalnie wpływających na nasilenie zmian należą stres i zaburzenia nastroju [5]. Najczęstszą odmianą choroby jest łuszczyca zwyczajna, a wśród innych postaci należy wymienić łuszczycę kropelkową, krostkową oraz erytrodermię łuszczycową. Stopień nasilenia procesu łuszczycowego określa się za pomocą wskaźnika PASI (Psoriasis Area Severity Index) [6]. W utrzymywaniu się łuszczycy oraz występowaniu zaostrzeń pewną rolę mogą odgrywać uwarunkowania środowiskowe i genetyczne [7]. Również niektóre czynniki immunologiczne mogą mieć działanie prozapalne i wpływać na rozprzestrzenianie się odpowiedzi zapalnej w przebiegu łuszczycy [8, 9].

Ślina jest płynem biologicznym zawierającym ważne markery biologiczne, a przy tym materiałem, który umożliwia proste pobieranie próbek i ich przechowywanie [10]. Mimo że analiza biomarkerów obecnych w ślinie jest wykonywana w niektórych chorobach układowych, wciąż istnieje niewiele doniesień dotyczących występowania w ślinie biomarkerów związanych z łuszczycą [11]. W niedawnym przeglądzie wykazano, że biomarkery obecne w ślinie mogą być przydatne w ocenie nasilenia i progresji łuszczycy i mogą stanowić wartościowy wskaźnik w przyszłych zastosowaniach [12]. 
based on case-control studies for the first time in a meta-analysis.

\section{MATERIAL AND METHODS}

\section{Search strategy}

One author (M.S.) accomplished the initial search, and another author (H.N.) rechecked them. Differences between the 2 authors were resolved by discussion. A comprehensive search was conducted on salivary levels of some biomarkers in psoriatic patients compared with controls. The PubMed/Medline, Scopus, Web of Science, and Cochrane Library databases were searched from the beginning of each database until 25 June 2019 without any restrictions. The search keywords were ("psoriasis" or "psoriatic") and ("saliva" or "salivary"). A manual search among other databases was done by the same author (M.S.) to find any missed articles. In addition, salivary biomarkers were included in the meta-analysis for studd having at least 2 articles (fig. 1).

\section{Eligibility criteria}

Inclusion criteria were as follows: (a) case-control studies; (b) studies including salivary biomarkers on stimulated or unstimulated levels and having at least 2 articles; and (c) studies providing mean (standard deviation (SD)) or event rate (percent) in psoriatic patients and controls. Exclusion criteria were as follows: (a) studies not related to the salivary levels; (b) review, letter to the editor, and conference papers; (c) studies containing overlapping data; and (d) studies with 1 article reporting salivary biomarkers.

\section{Data extraction}

Two authors (H.N. and M.S.) independently retrieved the data of each study included in the systematic review based on the criteria. Disagreements between the 2 authors were resolved through further discussion. The extracted data are presented in table 1.

\section{Statistical analysis}

One author (M.S.) analysed the data and the other author (H.N.) independently rechecked them. Differences among the authors were resolved via discussion. The mean differences (MDs) or odds ratios (ORs) with corresponding 95\% confidence intervals (CIs) in all analyses were determined by Review Manager 5.3 software. Heterogeneity across the studies was estimated using both the Cochrane Q test $[13,14]$ and $I^{2}$ metric $[15,16]$, ranging from 0 to $100 \%$ [17]. There was a statistically significant heterogeneity if $p$-value $<0.1$ and $I^{2}>50 \%$, in which case the random-effect model was used to estimate the pooled OR/MDs and CI val-

\section{CEL PRACY}

Celem pracy było badanie biomarkerow śliny jako czynników prognostycznych u pacjentów z łuszczycą. Przeprowadzona metaanaliza dostępnych badań kliniczno-kontrolnych po raz pierwszy poddaje ocenie biomarkery występujące $\mathrm{w}$ ślinie pacjentów $\mathrm{z}$ łuszczycą pod kątem ich przydatności prognostycznej.

\section{MATERIAŁ I METODY}

\section{Strategia selekcji badań}

Jeden z autorów (M.S.) dokonał wstępnej kwerendy, natomiast drugi autor (H.N.) przeprowadził jej weryfikację. Różnice zdań pomiędzy autorami rozwiązywano w drodze dyskusji. Przeprowadzono dokładne przeszukiwanie baz danych pod kątem opublikowanych prac dotyczących stężeń niektórych biomarkerów w ślinie u pacjentów z łuszczycą $\mathrm{w}$ porównaniu z grupą kontrolną. Uwzględniono bazy danych PubMed/Medline, Scopus, Web of Science i Cochrane Library od początku ich istnienia do 25 czerwca 2019 roku, bez żadnych ograniczeń. Wyszukiwanie przeprowadzono przy użyciu słów kluczowych: „psoriasis” lub „psoriatic” oraz „saliva” lub "salivary”. W celu wyszukania ewentualnych pominiętych prac jeden $\mathrm{z}$ autorów (M.S.) dodatkowo dokonał ręcznego przeszukania innych baz danych. Biomarker został włączony do metaanalizy, jeżeli był uwzględniony w co najmniej dwóch publikacjach (ryc. 1).

\section{Kryteria kwalifikacyjne}

Kryteria włączenia: a) badania kliniczno-kontrolne; b) badania obejmujące biomarkery obecne w ślinie w stężeniach stymulowanych lub niestymulowanych, opisane w co najmniej dwóch publikacjach; oraz c) prace określające średnie (odchylenie standardowe (SD)) lub częstości występowania zdarzeń (odsetki) u pacjentów z łuszczycą i w grupie kontrolnej. Kryteria wyłączenia: a) badania, które nie obejmowały stężeń biomarkerów $\mathrm{w}$ ślinie; b) recenzje, listy do redakcji i wystąpienia konferencyjne; c) badania zawierające pokrywające się dane; oraz d) pojedyncze prace dotyczące poszczególnych biomarkerów w ślinie.

\section{Ekstrakcja danych}

Na podstawie zdefiniowanych kryteriów obaj autorzy (H.N. i M.S.) niezależnie wyodrębnili dane $\mathrm{z}$ badań objętych systematycznym przeglądem. Różnice zdań pomiędzy autorami rozwiązywano w drodze dyskusji. Dane wyodrębnione według procedury przedstawiono $\mathrm{w}$ tabeli 1.

\section{Analiza statystyczna}

Jeden z autorów (M.S.) dokonał analizy danych, a drugi (H.N.) przeprowadził ich niezależną weryfikację. Różnice zdań pomiędzy autorami rozwiązy- 

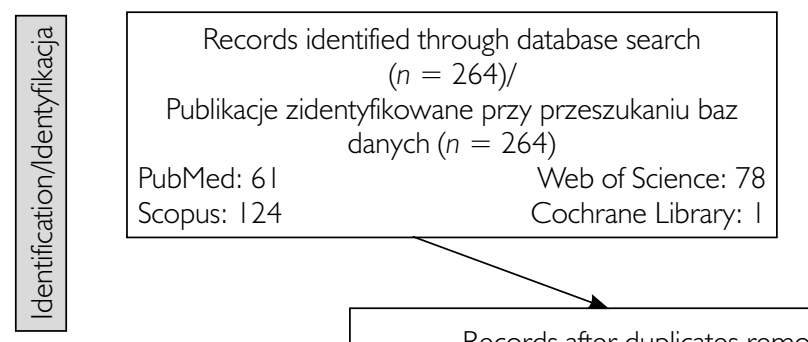

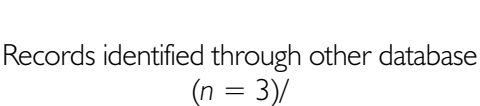

Publikacje zidentyfikowane $w$ innych bazach danych $(n=3)$

Scopus: 124 Cochrane Library:

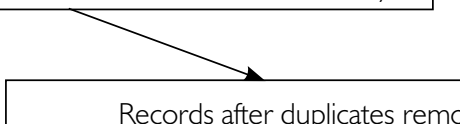

Records after duplicates removed $(n=177) /$

Publikacje po usunięciu prac zdublowanych $(n=177)$
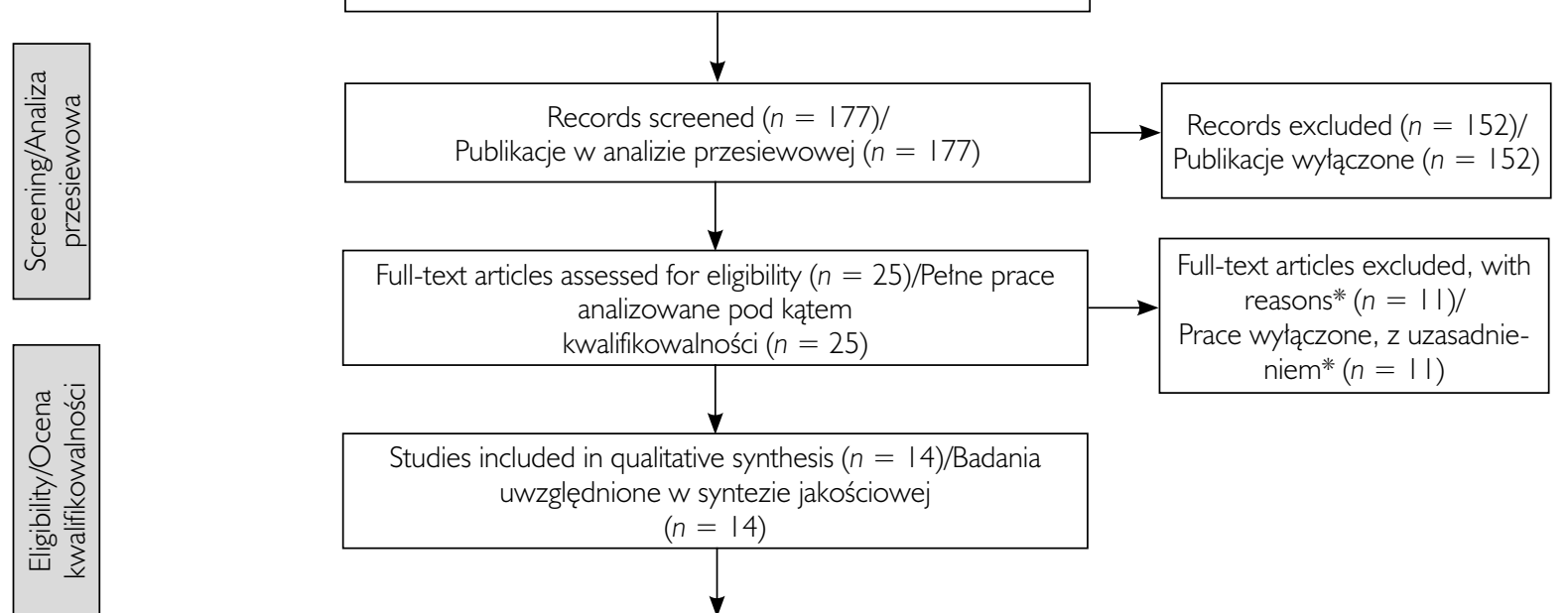

Studies included in qualitative synthesis $(n=14)$ /Badania uwzględnione w syntezie jakościowej $(n=14)$

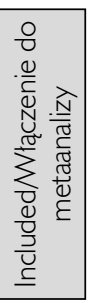

Studies included in quantitative synthesis (meta-analysis) $(n=14) /$

Badania uwzględnione w syntezie ilościowej (metaanalizie) $(n=14)$

* I study was a review; I study was a letter to the editor; 5 studies had no sufficient data; 4 studies reported other salivary factors/ *I praca przeglądowa, I list do redakcji, 5 prac niezawierających wystarczających danych, 4 prace dotyczące innych parametrów w ślinie

Figure I. Flow-chart of the study selection

Rycina I. Schemat blokowy selekcji badań

ues. Otherwise, the fixed-effect model with $p<0.05$ (2-tailed) was considered statistically significant.

\section{RESULTS}

Out of 264 records retrieved from the databases and 3 records through other databases, 177 records were screened after removing the duplicate ones (table 1). Among the screened records, 152 records were irrelevant and were therefore excluded. Thus, 25 articles were assessed for eligibility based on their full text. Among the 25 articles, 11 articles were excluded with reasons (1 study was a review; 1 study was a letter to the editor; 5 studies had no sufficient data; and 4 studies reported other salivary biomarkers having 1 article). Finally, 14 studies were included and analysed in the meta-analysis.

The characteristics of the 14 studies included in the meta-analysis are shown in table 1 . The studies had been wano w drodze dyskusji. Średnie różnice (mean difference - MD) lub ilorazy szans (odds ratio - OR) wraz $\mathrm{z}$ odpowiednimi $95 \%$ przedziałami ufności (confidence interval - CI) we wszystkich analizach obliczono za pomocą oprogramowania Review Manager 5.3. Heterogeniczność badań określano przy zastosowaniu testu Q Cochrana $[13,14]$ i wskaźnika $I^{2}[15,16]$, w przedziale od 0 do 100\% [17]. Heterogeniczność uznawano za znamienną statystycznie przy wartości $p<0,1$ i $I^{2}>50 \%$. Stosowano wówczas model efektów losowych do oszacowania zbiorczych wartości OR/MD i CI. W pozostałych przypadkach stosowano model efektów stałych (2-stronny) z wartością $p<0,05$ jako wyznacznikiem znamienności statystycznej.

\section{WYNIKI}

Spośród 264 publikacji wyszukanych w bazach danych oraz 3 pozyskanych za pośrednictwem innych 
Table I. Characteristics of studies included in the meta-analysis $(n=14)$

Tabela I. Charakterystyka badań włączonych do metaanalizy $(n=14)$

\begin{tabular}{|c|c|c|c|c|}
\hline $\begin{array}{l}\text { First author, publication } \\
\text { year/Pierwszy autor, rok } \\
\text { publikacji }\end{array}$ & Country/Kraj & $\begin{array}{l}\text { No. of patients/ } \\
\text { Liczba } \\
\text { pacjentów }\end{array}$ & $\begin{array}{l}\text { No. of controls/ } \\
\text { Liczebność grupy } \\
\text { kontrolnej }\end{array}$ & $\begin{array}{l}\text { Salivary biomarker/ } \\
\text { Biomarker obecny w ślinie }\end{array}$ \\
\hline Oon, $1973[$ [ 8] & $\begin{array}{l}\text { Great Britain/ } \\
\text { Wielka Brytania }\end{array}$ & 12 & 12 & $\lg A / \lg A$ \\
\hline Guilhou, 1976 [24] & France/Francja & 28 & 40 & $\lg A / \lg A$ \\
\hline Syrjänen, 1983 [25] & Finland/Finlandia & 28 & 28 & $\begin{array}{l}\text { Flow rate, sodium, potassium, chloride, } \\
\alpha \text {-amylase, IgA/Natężenie przepływu, } \\
\text { sód, potas, chlorki, } \alpha \text {-amylaza, lgA }\end{array}$ \\
\hline $\begin{array}{l}\text { del Castillo Carrillo, | } 981 \\
\text { [22] }\end{array}$ & Germany/Niemcy & 10 & 10 & $\lg A / \lg A$ \\
\hline Marsden, 1984 [19] & $\begin{array}{c}\text { Great Britain/ } \\
\text { Wielka Brytania }\end{array}$ & 41 & 41 & Antipyrine clearance/Klirens antypiryny \\
\hline Kubota, 1986 [26] & Japan/Japonia & 10 & 20 & Antipyrine clearance/Klirens antypiryny \\
\hline Waldman, 200। [27] & Israel//zrael & 50 & 50 & Candida/Candida \\
\hline $\begin{array}{l}\text { Buske-Kirschbaum, } 2006 \\
\text { [23] }\end{array}$ & Germany/Niemcy & 23 & 25 & Cortisol/Kortyzol \\
\hline Mastrolonardo, 2007 [20] & ItalyMłochy & 25 & 50 & Interleukin- | $\beta /$ /nterleukina | $\beta$ \\
\hline Krasteva, 2009 [28] & Bulgaria/Bułgaria & 32 & 31 & $\lg A / \lg A$ \\
\hline Soudan, 20। I [29] & Syria/Syria & 20 & 20 & $\begin{array}{l}\text { Flow rate, sodium, potassium, chloride, } \\
\alpha \text {-amylase, IgA/Natężenie przepływu, } \\
\text { sód, potas, chlorki, } \alpha \text {-amylaza, IgA }\end{array}$ \\
\hline de Brouwer, 2014 [30] & Netherlands/Holandia & 30 & 25 & $\alpha$-amylase, cortisol $/ \alpha$-amylaza, kortyzol \\
\hline Pezeshkpoor, 2015 [6] & Iran/Iran & 50 & 50 & Candida/Candida \\
\hline Ganzetti, 2016 [2।] & ItalyMłochy & 25 & 20 & Interleukin- | $\beta /$ Interleukina | $\beta$ \\
\hline
\end{tabular}

published from 1973 to 2016 . Two studies were reported from England [18, 19], 2 from Italy [20, 21], two from Germany [22, 23], and 1 from each of the following countries: France [24], Finland [25], Japan [26], Israel [27], Bulgaria [28], Syria [29], the Netherlands [30], and Iran [6].

Salivary $\alpha$-amylase, cortisol, IgA, and interleukin-I $\beta$ levels

The pooled analyses of salivary a-amylase, cortisol, $\operatorname{IgA}$, and interleukin-1 $\beta$ levels are shown in figure 2 . The pooled MDs of a-amylase, cortisol, IgA, and interleukin$1 \beta$ were $12.69 \mathrm{IU} / \mathrm{ml}(95 \% \mathrm{CI}: 10.59,14.79 ; p<0.00001$; $I^{2}=0 \%\left(p_{\text {heterogeneity }}\right.$ or $\left.\left.p_{h}=0.63\right)\right),-2.03 \mathrm{nmol} / 1(95 \% \mathrm{CI}$ : $\left.-4.34,0.27 ; p=0.08 ; I^{2}=76 \%\left(p_{h}=0.04\right)\right), 4.46 \mathrm{mg} / \mathrm{dl}$ (95\% CI: $\left.-1.08,10.00 ; p=0.11 ; I^{2}=97 \%\left(p_{h}<0.00001\right)\right)$, $1.60 \mathrm{pg} / \mathrm{ml}$ (95\% CI: 1.45, 1.75; $p<0.00001 ; I^{2}=0 \%$ $\left.\left(p_{h}=0.90\right)\right)$, respectively. The results showed that $\alpha$-amylase and interleukin- $1 \beta$ levels were significantly higher in the psoriatic patients than in the controls.

Salivary candida incidence, antipyrine clearance, sodium, potassium, chloride, and flow rate levels

The pooled analyses of salivary candida incidence, antipyrine clearance, sodium, potassium, chloride, and flow rate levels are shown in figure 3 . The pooled OR of salivary candida incidence was 7.64 (95\% CI: baz, po usunięciu zdublowanych, analizą przesiewową objęto 177 publikacji (tab. 1). Wśród publikacji poddanych analizie przesiewowej łącznie 152 nie miało związku z przedmiotem metaanalizy i zostało wykluczonych. W ten sposób otrzymano 25 publikacji, które na podstawie pełnej treści poddano ocenie pod kątem kryteriów kwalifikacyjnych. Jedenaście spośród 25 publikacji wykluczono z odpowiednim uzasadnieniem (1 praca przeglądowa, 1 list do redakcji, 5 prac niezawierających wystarczających danych, 4 pojedyncze prace dotyczące innych biomarkerów w ślinie). Ostatecznie do metaanalizy włączono 14 badań, które poddano dalszej ocenie.

Charakterystykę 14 prac objętych metaanalizą przedstawiono w tabeli 1. Prace zostały opublikowane od 1973 do 2016 roku. Zbiór obejmował po dwa badania z Wielkiej Brytanii [18, 19], Włoch [20, 21] i Niemiec [22, 23] oraz po jednym z Francji [24], Finlandii [25], Japonii [26], Izraela [27], Bułgarii [28], Syrii [29], Holandii [30] i Iranu [6].

\section{Stężenia $\alpha$-amylazy, kortyzolu, IgA $\mathrm{i}$ interleukiny I $\beta \mathrm{w}$ ślinie}

Analizę zbiorczą stężeń a-amylazy, kortyzolu, IgA $\mathrm{i}$ interleukiny $1 \beta \mathrm{w}$ ślinie przedstawiono na rycinie 2. Wartości zbiorcze MD dla a-amylazy, kortyzolu, 


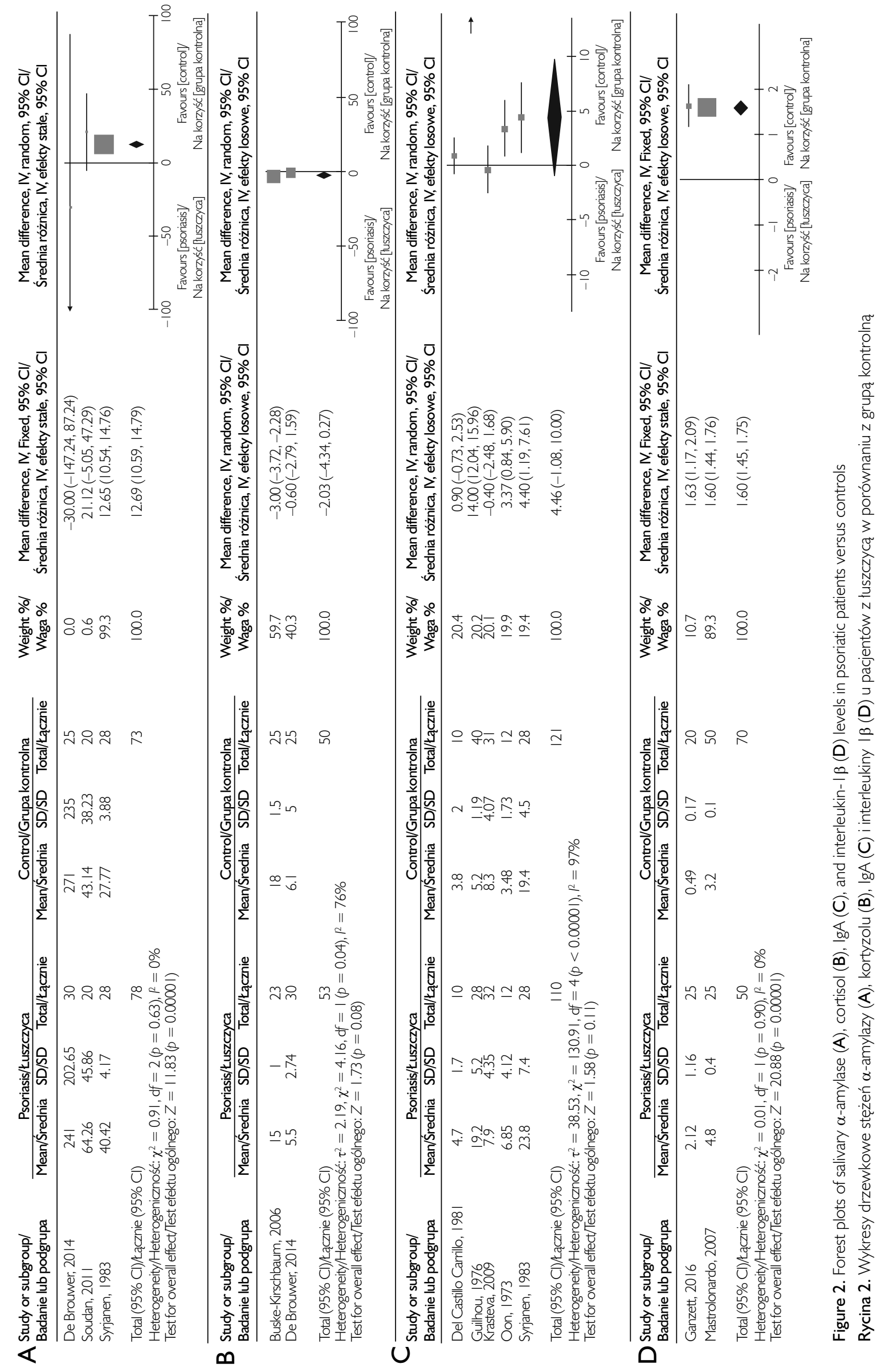


$\left.1.08,54.18 ; p=0.04 ; I^{2}=69 \%\left(p_{h}=0.07\right)\right)$. Furthermore, the pooled MDs of antipyrine clearance, sodium, potassium, chloride, and flow rate levels were $-2.11 \mathrm{ml} / \mathrm{h}$ $\times \mathrm{kg}\left(95 \% \mathrm{CI}:-12.98,8.76 ; p=0.70 ; I^{2}=83 \%\left(p_{h}=0.02\right)\right)$, $4.51 \mathrm{mmol} / 1$ (95\% CI: $-7.68,16.70 ; p=0.47 ; I^{2}=79 \%$ $\left.\left(p_{h}=0.03\right)\right), 1.69 \mathrm{mmol} / 1$ (95\% CI: $-1.58,4.96 ; p=0.31$; $\left.I^{2}=64 \%\left(p_{h}=0.09\right)\right), 2.60 \mathrm{mmol} / 1$ (95\% CI: $-3.03,8.23$; $\left.p=0.37 ; I^{2}=0 \%\left(p_{h}=0.73\right)\right), 0.12 \mathrm{ml} / 5 \mathrm{~min}(95 \% \mathrm{CI}$ : $\left.-0.35,0.60 ; p=0.61 ; I^{2}=42 \%\left(p_{h}=0.19\right)\right)$, respectively.

\section{DISCUSSION}

Psoriasis is a chronic and multifactorial inflammatory disease associated with the immune system [31]. Psychosocial stress can be a risk factor for maintaining and exacerbating psoriasis [30]. The present metaanalysis showed that some salivary biomarkers such as $\alpha$-amylase, interleukin-1 $\beta$, and candida incidence were significantly higher in the psoriatic patients than in the controls.

Three studies included in this meta-analysis [25, 29,30 ] checked salivary a-amylase levels, of which 1 study [25] showed a significantly increased level and 2 other studies did not report any significant level in psoriatic patients compared to controls. Out of 2 studies $[23,30]$ reporting salivary cortisol levels, 1 study [23] reported a significantly decreased level in the patients compared to controls and another did not show a significant difference between the 2 groups. Five studies $[18,22,24,25,28]$ checked salivary IgA levels in the patients versus the controls. The results of 3 studies [18, 24, 25] showed a significantly increased level in psoriatic compared to controls. Examining interleukin- $1 \beta$ in 2 studies $[20,21]$, both reported a significantly increased level in the patients compared to controls. Candida incidence was investigated in 2 studies [6, 27], both of which showed a significant incidence in psoriatic patients compared with controls. Antipyrine clearance was also investigated in 2 studies [19, 26], 1 of which [19] showed a significantly decreased level in the patients versus controls. The salivary sodium, potassium, chloride, and flow rate levels were evaluated in 2 studies [25, 29]. Sodium in 1 study [25] and potassium in another study [29] were significantly increased in the patients compared with controls.

Investigating other studies that were not included in the meta-analysis, Koh et al. [32] reported a lower concentration and secretion rate for salivary $\operatorname{IgA}$ in the patients compared to controls. Moreover, Singh et al. [33] showed that salivary sodium levels were significantly increased in psoriasis, while there was no significant rise in salivary potassium levels. However, potassium levels were significantly correlated with the severity of psoriasis.
IgA i interleukiny $1 \beta$ wyniosły odpowiednio 12,69 IU / ml (95\% CI: 10,59; 14,79; $p<0,00001 ; I^{2}=0 \%\left(p_{\text {he- }}\right.$ terog. lub $\left.\left.p_{h}=0,63\right)\right),-2,03 \mathrm{nmol} / 1$ (95\% CI: $-4,34 ; 0,27$; $\left.p=0,08 ; I^{2}=76 \%\left(p_{h}=0,04\right)\right) ; 4,46 \mathrm{mg} / \mathrm{dl}(95 \% \mathrm{CI}$ : $\left.-1,08 ; 10,00 ; p=0,11 ; I^{2}=97 \%\left(p_{h}<0,00001\right)\right) ; 1,60 \mathrm{pg} /$ $\operatorname{ml}\left(95 \%\right.$ CI: 1,$\left.45 ; 1,75 ; p<0,00001 ; I^{2}=0 \%\left(p_{h}=0,90\right)\right)$. Na podstawie uzyskanych wyników ustalono, że stężenia a-amylazy i interleukiny $1 \beta$ są znamiennie podwyższone $\mathrm{u}$ pacjentów $\mathrm{z}$ łuszczycą $\mathrm{w}$ porównaniu z grupą kontrolną.

\section{Częstość występowania Candida, klirens antypiryny, stężenia sodu, potasu i chlorków oraz natężenie przepływu śliny}

Analizy zbiorcze częstości występowania drożdży $\mathrm{z}$ rodzaju Candida w ślinie, klirensu antypiryny, stężeń sodu, potasu i chlorków oraz natężenia przepływu śliny przedstawiono na rycinie 3 . Zbiorcza wartość OR dla częstości występowania Candida w ślinie wyniosła 7,64 (95\% CI: 1,08; 54,18; $p=0,04 ; I^{2}=69 \%$ $\left.\left(p_{h}=0,07\right)\right)$. Zbiorcze wartości MD dla klirensu antypiryny, stężeń sodu, potasu i chlorków oraz natężenia przepływu śliny wyniosły odpowiednio $-2,11 \mathrm{ml} / \mathrm{h} \times$ kg (95\% CI: $\left.-12,98 ; 8,76 ; p=0,70 ; I^{2}=83 \%\left(p_{h}=0,02\right)\right)$; $4,51 \mathrm{mmol} / 1$ (95\% CI: $-7,68 ; 16,70 ; p=0,47 ; I^{2}=79 \%$ $\left.\left(p_{h}=0,03\right)\right) ; 1,69 \mathrm{mmol} / 1$ (95\% CI: $-1,58 ; 4,96 ; p=0,31$; $\left.I^{2}=64 \%\left(p_{h}=0,09\right)\right) ; 2,60 \mathrm{mmol} / 1(95 \% \mathrm{CI}:-3,03 ; 8,23$; $\left.p=0,37 ; I^{2}=0 \%\left(p_{h}=0,73\right)\right) ; 0,12 \mathrm{ml} / 5 \mathrm{~min}(95 \% \mathrm{CI}$ : $\left.-0,35 ; 0,60 ; p=0,61 ; I^{2}=42 \%\left(p_{h}=0,19\right)\right)$.

\section{OMÓWIENIE}

Łuszczyca jest przewlekłą, wieloczynnikową chorobą zapalną o podłożu immunologicznym [31]. Czynnikiem ryzyka sprzyjającym utrzymywaniu się łuszczycy i występowaniu zaostrzeń może być stres psychospołeczny [30]. Przeprowadzona metaanaliza wykazała, że stężenia niektórych biomarkerów obecnych w ślinie, takich jak a-amylaza i interleukina $1 \beta$, a także częstość występowania drożdży z rodzaju Candida, były znamiennie podwyższone u pacjentów z łuszczycą w porównaniu z grupą kontrolną.

W trzech badaniach objętych metaanalizą [25, 29, 30] oznaczano stężenie a-amylazy. W jednym badaniu [25] stwierdzono znamiennie wyższe stężenia, natomiast $\mathrm{w}$ pozostałych dwóch nie wykazano znamiennie wyższych stężeń u pacjentów z łuszczycą w porównaniu z grupą kontrolną. Spośród dwóch badań [23, 30], w których analizowano stężenie kortyzolu w ślinie, w jednym [23] odnotowano znamienne zmniejszenie stężenia $\mathrm{u}$ chorych na łuszczycę w porównaniu z grupą kontrolną, a w drugim nie wykazano znamiennej różnicy pod względem stężenia kortyzolu pomiędzy grupami. W pięciu badaniach $[18,22$, 24, 25, 28] oznaczano stężenie IgA w ślinie pacjentów 


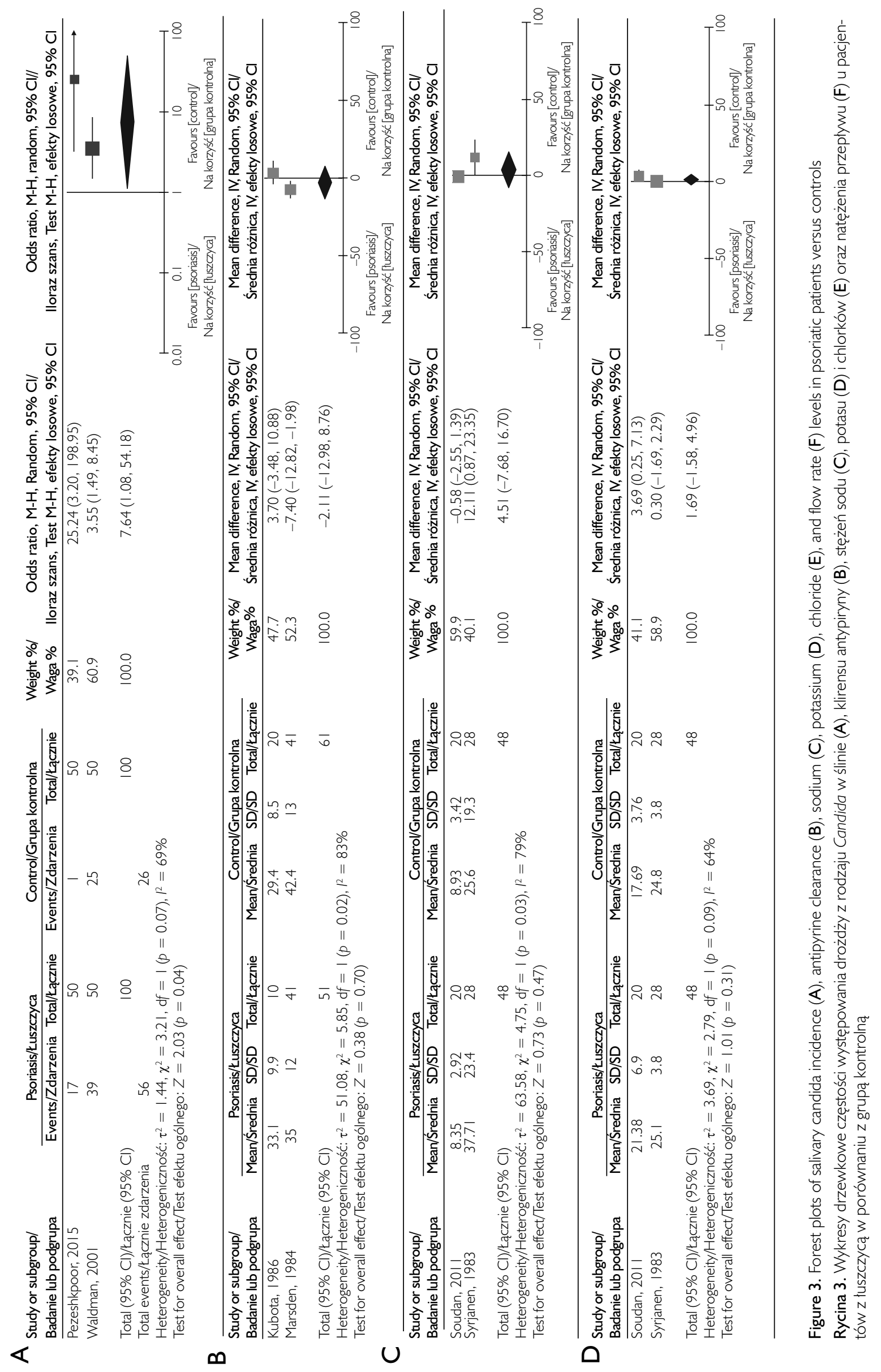




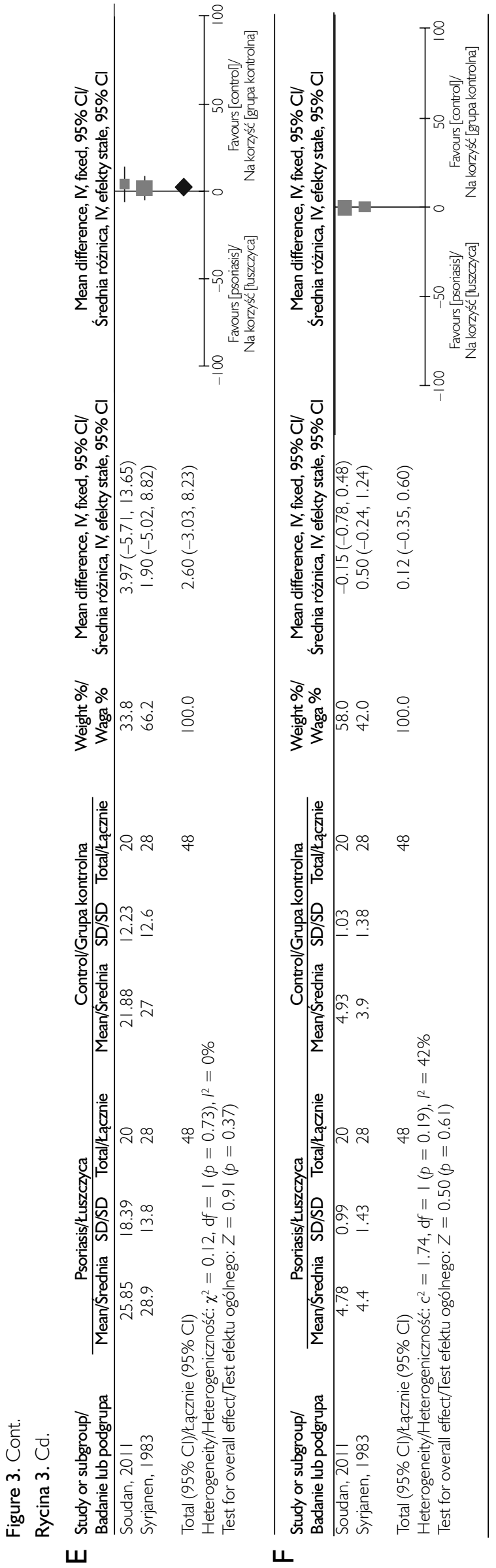

w porównaniu z grupą kontrolną. Wyniki trzech badań $[18,24,25]$ wykazały znamiennie podwyższone stężenie IgA u chorych na łuszczycę w stosunku do grupy kontrolnej. Interleukinę $1 \beta$ analizowano w dwóch badaniach [20, 21]. W obu stwierdzono znamienny wzrost jej stężenia u pacjentów z łuszczycą w porównaniu z grupą kontrolną. Częstość występowania drożdży z rodzaju Candida analizowano w dwóch badaniach $[6,27]$. W obu była ona znamiennie podwyższona u pacjentów z łuszczycą $\mathrm{w}$ porównaniu $\mathrm{z}$ grupą kontrolną. Klirens antypiryny również oceniano $\mathrm{w}$ dwóch badaniach $[19,26]$, z których jedno wykazało znamiennie obniżony jego poziom u chorych na łuszczycę $\mathrm{w}$ porównaniu z grupą kontrolną [19]. W dwóch badaniach analizowano stężenia sodu, potasu i chlorków oraz natężenie przepływu śliny [25, 29]. W jednym wykazano znamiennie podwyższone stężenie sodu [25], a w drugim znamiennie podwyższone stężenie potasu w porównaniu z grupą kontrolną [29].

Analizowano także inne badania, które nie zostały uwzględnione w metaanalizie. Koh i wsp. [32] opisali obniżone stężenie i natężenie wydzielania IgA w ślinie u pacjentów $\mathrm{z}$ łuszczycą $\mathrm{w}$ porównaniu $\mathrm{z}$ grupą kontrolną. Ponadto Singh i wsp. [33] zaobserwowali, że stężenie sodu w ślinie jest znamiennie podwyższone w przebiegu łuszczycy. Nie stwierdzono natomiast znamiennego wzrostu stężenia potasu w ślinie. Stężenie potasu wykazywało $\mathrm{z}$ kolei istotną korelację ze stopniem nasilenia łuszczycy.

Na podstawie uzyskanych wyników stwierdzono różnice między wynikami badań uwzględnionych w metaanalizie dotyczące stężeń biomarkerów obecnych $w$ ślinie. $W$ przypadku innych biomarkerów występujących $w$ ślinie, m.in. białek o strukturze harmonijki $\beta$, losowego zwoju i helisy $\alpha$ [34], hormonu adrenokortykotropowego [23], IgM [22], IgG [22, 28], czynników dotyczących jamy ustnej (stopnia wydzielania i zdolności buforowej śliny, obecności bakterii Streptococcus mutans i Lactobacillus) [35], lizosomu [32], białka całkowitego, haptoglobiny i białka C-reaktywnego [28], mocznika i $\beta 2$-mikroglobuliny [25], a także iryzyny [36], analizowanych u pacjentów z łuszczycą $\mathrm{w}$ porównaniu $\mathrm{z}$ grupą kontrolną $\mathrm{w}$ niektórych badaniach wykazano istotną różnicę między tymi grupami. Powyższe biomarkery nie zostały uwzględnione $\mathrm{w}$ przeprowadzonej metaanalizie, ponieważ badania, w których były analizowane, nie spełniały przyjętych kryteriów włączenia. Niespójność wyników może być skutkiem różnego pochodzenia etnicznego uczestników badań, warunków pobierania próbek i liczby uczestników, odmiennych klinicznych typów łuszczycy $[25,28,32]$ oraz ograniczeń metodologicznych $\mathrm{w}$ analizie biomarkerów obecnych w ślinie [37]. Przeprowadzona metaanaliza, którą objęto niewielką liczbę badań, uniemożliwiała weryfika- 
Based on the results, there were differences among studies in the salivary levels of the biomarkers investigated in the meta-analysis. However, other salivary biomarkers such as proteins ( $\beta$-sheets, random coils, and a-helixes) [34], adrenocorticotropic hormone [23], IgM [22], IgG [22, 28], oral parameters (secretion rate, buffer capacity, mutans streptococci, lactobacilli) [35], lysozyme [32], total protein, haptoglobin, and C-reactive protein [28]; urea and $\beta 2$-microglobulin [25]; and irisin [36] were evaluated in the patients compared to the controls, indicating a significant difference between the 2 groups in some studies. These biomarkers were not included in the present meta-analysis because the studies including these biomarkers did not follow the inclusion criteria. The contradictory results of the studies are probably due to different ethnicities, sampling conditions, numbers of participants, the different clinical types of psoriasis [25, 28, 32], and the methodological limits of salivary biomarkers [37], because this meta-analysis, including a low number of studies, could not check these factors and their effects on the levels of salivary biomarkers, and therefore further studies are needed in the future. The important limitations of the present meta-analysis were lack of subgroup analysis and high heterogeneity, probably because of the small sample size and scarcity of studies.

\section{CONCLUSIONS}

Although the number of studies in each analysis was low, several salivary parameters in psoriasis were shown in a meta-analysis for the first time. Some salivary biomarkers like a-amylase, interleukin-1 $\beta$, and candida incidence were significantly higher in the psoriatic patients than in the controls. Future studies with larger sample sizes are needed to confirm the results.

\section{ACKNOWLEDGMENTS}

We sincerely and gratefully thank Kermanshah University of Medical Sciences for providing the financial support.

\section{CONFLICT OF INTEREST}

The authors declare no conflict of interest. cję tych czynników i ich wpływu na stężenia biomarkerów obecnych w ślinie. Z tego względu potrzebne są dalsze badania w tym kierunku. Wśród istotnych ograniczeń metaanalizy należy wymienić brak analizy podgrup oraz duży stopień heterogeniczności wynikający prawdopodobnie z małej liczebności próby i niewielkiej liczby uwzględnionych badań.

\section{WNIOSKI}

Mimo że liczby prac dotyczących poszczególnych biomarkerów były niewielkie, w przeprowadzonej metaanalizie po raz pierwszy uwzględniono kilka istotnych parametrów śliny w przebiegu łuszczycy. Stężenia niektórych biomarkerów obecnych w ślinie, takich jak a-amylaza czy interleukina $1 \beta$, a także częstość występowania drożdży z rodzaju Candida były znamiennie wyższe $u$ chorych na łuszczycę niż u osób z grupy kontrolnej. Aby zweryfikować uzyskane wyniki, potrzebne są jednak dalsze badania na próbie o większej liczebności.

\section{PODZIEKKOWANIA}

Serdecznie dziękujemy uczelni Kermanshah University of Medical Sciences za fundusze na przeprowadzenie badania.

\section{KONFLIKT INTERESÓW}

Autorzy nie zgłaszają konfliktu interesów. 


\section{References}

Piśmiennictwo

1. Nemati H., Khodarahmi R., Sadeghi M., Ebrahimi A., Rezaei M., Vaisi-Raygani A.: Antioxidant status in patients with psoriasis. Cell Biochem Funct 2014, 32, 268-273.

2. Nemati H., Ghahramani M.H., Faridi-Majidi R., Izadi B., Bahrami G., Madani S.H., et al.: Using siRNA-based spherical nucleic acid nanoparticle conjugates for gene regulation in psoriasis. J Control Release 2017, 268, $259-268$.

3. Myers W.A., Gottlieb A.B., Mease P.: Psoriasis and psoriatic arthritis: clinical features and disease mechanisms. Clin Dermatol 2006, 24, 438-447.

4. Hussain I., Haroon T.S.: Comorbidities in psoriasis and their therapeutic implications. J Pak Assoc Dermatol 2009, 19 , 63-65.

5. Verhoeven E.W., Kraaimaat F.W., Jong E.M., Schalkwijk J., van de Kerkhof P.C., Evers A.W.: Effect of daily stressors on psoriasis: a prospective study. J Invest Dermatol 2009, 129, 2075-2077.

6. Pezeshkpoor F., Yazdanpanah M.J., Zaman Family S., Sepahi S., Moghaddas E., Shamsian A.: Prevalence of Candida in saliva and skin lesions of psoriasis vulgaris patients. JMR 2015, 2, 9-14.

7. Taheri Sarvtin M., Shokohi T., Hajheydari Z., Yazdani J., Hedayati M.T.: Evaluation of candida colonization and specific humoral responses against Candida albicans in patients with psoriasis. Int J Dermatol 2014, 53, 1423-1541.

8. Schon M., Behmenburg C., Denzer D., Schon M.P.: Pathogenic function of IL-1 beta in psoriasiform skin lesions of flaky skin (fsn/fsn) mice. Clin Exp Immunol 2001, 123, 505-510.

9. Griffiths C.E.: The immunological basis of psoriasis. J Eur Acad Dermatol Venereol 2003, 17, 1-5.

10. Farnaud S.J., Kosti O., Getting S.J., Renshaw D.: Saliva: physiology and diagnostic potential in health and disease. Sci World J 2010, 10, 434-456.

11. Malamud D.: Saliva as a diagnostic fluid. Dent Clin North Am 2012, 55, 159-178.

12. Asa'ad F., Fiore M., Alfieri A., Maria Pigatto P.D., Franchi C., Berti E., et al.: Saliva as a future field in psoriasis research. Biomed Res Int 2018, 2018, 7290913.

13. Zintzaras E., Ioannidis J.P.: Heterogeneity testing in meta-analysis of genome searches. Genet Epidemiol 2004, 24, 1-15.

14. Zintzaras E., Hadjigeorgiou G.M.: The role of G196A polymorphism in the brain-derived neurotrophic factor gene in the cause of Parkinson's disease: a meta-analysis. J Hum Genet 2005, 50, 560-566.

15. Higgins J.P., Thompson S.E.: Quantifying heterogeneity in a metaanalysis. Stat Med 2002, 21, 1539-1558.

16. Higgins J.P., Thompson S.G., Deeks J.J., Altman D.G.: Measuring inconsistency in meta analyses. Br Med J 2003, 327, 557-560.

17. Begg C.B., Mazumdar M.: Operating characteristics of a rank correlation test for publication bias. Biometrics 1994, 50, 10881101.

18. Oon C.H., Goodwin P.G., Kind P.R., Seah P.P., Fry L.: Salivary IgA in patients with psoriasis and dermatitis herpetiformis. Acta Derm Venereol 1973, 53, 340-342.

19. Marsden J.R., Williams F.M., Keys B., Rawlins M.D., Shuster S.: Reduction of antipyrine clearance in psoriasis. Br J Clin Pharmacol 1984, 17, 331-333.

20. Mastrolonardo M., Alicino D., Zefferino R., Pasquini P., Picardi A.: Effect of psychological stress on salivary interleukin-1beta in psoriasis. Arch Med Res 2007, 38, 206-211.

21. Ganzetti G., Campanati A., Santarelli A., Sartini D., Molinelli E., Brisigotti V., et al.: Salivary interleukin-1 $\beta$ : oral inflammatory biomarker in patients with psoriasis. J Int Med Res 2016, 44, 10-14.

22. del Castillo Carrillo L.F., Schwarz W., Hornstein O.P.: Immunoglobulins in serum, whole saliva, and parotid saliva of male healthy and psoriatic individuals. Arch Dermatol Res 1981, 271, 63-71.

23. Buske-Kirschbaum A., Ebrecht M., Kern S., Hellhammer D.H.: Endocrine stress responses in Th1-mediated chronic inflammatory skin disease (psoriasis vulgaris) - do they parallel stress-induced endocrine changes in Th2-mediated inflammatory dermatoses (atopic dermatitis)? Psychoneuroendocrinology 2006, 31, 439-446.

24. Guilhou J.J., Meynadier J., Clot J., Charmasson E., Dardenne M., Brochier J.: Immunological aspects of psoriasis. Br J Derm 1976, 94, 501-507.

25. Syrjänen S.M.: Chemical analysis of parotid saliva and lacrimal fluid in psoriatics. Arch Dermatol Res 1983, 275, $152-155$.

26. Kubota K., Ishizaki T., Chiba K., Takagi A., Nakagawa A., Nakamura K.: Antipyrine clearance and metabolism in patients with psoriasis. Br J Clin Pharmacol 1986, 22, 455-462.

27. Waldman A., Gilhar A., Duek L., Berdicevsky I.: Incidence of Candida in psoriasis: a study on the fungal flora of psoriatic patients. Mycoses 2001, 44, 77-81.

28. Krasteva A., Grozdev I., Ivanova A., Altankova I., Bocheva S., Kisselova A., et al.: Psoriatic patients and salivary components. OHDMBSC 2009, 8, 12-15.

29. Soudan R.A., Daoud S.A., Mashlah A.M.: Study of some salivary changes in cutaneous psoriatic patients. Saudi Med J 2011, 32, 386-389.

30. de Brouwer S.J., van Middendorp H., Stormink C., Kraaimaat F.W., Sweep F.C., de Jong E.M., et al.: The psychophysiological stress response in psoriasis and rheumatoid arthritis. Br J Dermatol 2014, 170, 824-831.

31. Preus H.R., Khanifam P., Kolltveit K., Mørk C., Gjermo P.: Periodontitis in psoriasis patients: a blinded, case-controlled study. Acta Odontol Scand 2010, 68, 165-170.

32. Koh D., Yang Y., Khoo L., Nyunt S.Z., Ng V., Goh C.L.: Salivary immunoglobulin A and lysozyme in patients with psoriasis. Ann Acad Med Singapore 2004, 33, 307-310.

33. Singh G., Rajashekar T.S., Krishnamurthy Haneef N.: Salivary electrolytes in psoriasis: a preliminary study. Indian J Dermatol 2006, 51, 192-193. 
34. Bottoni U., Tiriolo R., Pullano S.A., Dastoli S., Amoruso G.F., Nisticò S.P., et al.: Infrared saliva analysis of psoriatic and diabetic patients: similarities in protein components. IEEE Trans Biomed Eng 2016, 63, 379-384.

35. Fadel H.T., Flytström I., Calander A.M., Bergbrant I.M., Heijl L., Birkhed D.: Profiles of dental caries and periodontal disease in individuals with or without psoriasis. J Periodontol 2013, 84, 477-485.

36. Tugba Alatas E., Kalayci M., Kara A., Dogan, G.: Association between insulin resistance and serum and salivary irisin levels in patients with psoriasis vulgaris. Dermatol Sin 2017, 35, 12-15.

37. Ganzetti G., Campanati A., Santarelli A., Pozzi V., Molinelli E., Minnetti I., et al.: Involvement of the oral cavity in psoriasis: results of a clinical study. Br J Dermatol 2015, 172, 282-285.

Received: 17.06 .2020

Accepted: 9.02.2021

Otrzymano: $17.06 .2020 \mathrm{r}$.

Zaakceptowano: 9.02.2021 r.

How to cite this article

Nemati H., Sadeghi M.: Salivary biomarkers in patients with psoriais - a meta-analysis. Dermatol Rev/Przegl Dermatol 2021, 108, 105-116. DOI: https://doi.org/10.5114/dr.2021.107280. 